\title{
The Burden of Cost in Bronchiolitis Obliterans Syndrome: Predictions for the Next Decade
}

\author{
Christopher A. Jones ${ }^{1,3,4}$, David G. Chapman ${ }^{2,5}$, Peter Weimersheimer ${ }^{4}$, Luca Fernandez ${ }^{3}$, \\ Oscar Alejandro Mesa ${ }^{6}$, Christian Peters ${ }^{6}$, Bart M. Vanaudenaerde ${ }^{7}$, Mitchell C. \\ Norotsky ${ }^{4}$, Robin $\operatorname{Vos}^{7}$ \\ ${ }^{1}$ Vermont Cancer Center \\ ${ }^{2}$ Vermont Lung Center \\ ${ }^{3}$ Global Health Economics Unit of the Vermont Center for Clinical and Translational Science \\ ${ }^{4}$ Department of Surgery, University of Vermont College of Medicine, Burlington, Vermont, USA \\ ${ }^{5}$ Woolcock Institute of Medical Research, Sydney Medical School, University of Sydney, New South Wales, \\ Austrailia \\ ${ }^{6}$ Therakos, Inc., West Chester, PA, USA \\ ${ }^{7} \mathrm{KU}$ Leuven - University of Leuven, Department of Clinical and Experimental Medicine, Laboratory for \\ Respiratory Diseases, Lung Transplant Unit; University Hospitals Leuven, Department of Respiratory Diseases, \\ Lung Transplant and Respiratory Intermediate Care Unit, Leuven, Belgium \\ Corresponding author: chris.jones@vtmednet.org
}

\begin{abstract}
In health economics, costs can be divided into both direct and indirect categories. Direct costs tend to consist of medical costs, which are those directly attributed to health care interventions (e.g., hospitalizations, pharmaceuticals, devices), and non-medical direct costs such as monitoring and professional caregiving. Indirect costs tend to comprise those related to lost productivity due to illness (or treatment), burden on systems outside of the healthcare domain, and other costs that can sometimes outweigh the entire sum of direct healthcare costs.
\end{abstract}

The most common life-threatening complication of lung and hematopoietic stem-cell transplantation (HSCT) is bronchiolitis obliterans syndrome (BOS). BOS is currently diagnosed as a $20 \%$ decline in the forced expiratory volume in one second (FEV1) from the best (baseline) post-transplantation value, and is a major cause of morbidity and mortality amongst lung and stem cell transplant patients. BOS affects half of all lung transplant patients within the first 5 years post-transplant, rising to the majority of patients $(\sim 80 \%)$ within the first decade following transplant.

We estimated both direct and indirect costs for the first 10 years following BOS diagnosis, a viewpoint that highlights a tremendous imbalance between healthcare and non-healthcare costs. The lost workforce resulting from BOS-related infirmity will cost society more than $\$ 3.7$ Billion over the next decade, a figure that is more than double the estimated 10-year cost of treating BOS $(\$ 1.4 \mathrm{~B})$, including diagnostics, immunosuppressives, and additional complications. As such, BOS is estimated to present a burden of cost that must be evaluated in a new light to include the wider societal perspective. 


\section{INTRODUCTION}

Of all the present-day solid organs and tissues that can be transplanted, lungs and blood-producing stem cells present much higher rates of complication and rejection, both immediately following surgery and throughout the patient's life. The most common life-threatening complication of lung and hematopoietic stem-cell transplantation (HSCT) is a disease called bronchiolitis obliterans syndrome (BOS) in which the bronchioles proximal to the terminal airways become obstructed or obliterated due to airway narrowing. ${ }^{1} \mathrm{BOS}$ is currently diagnosed as a $20 \%$ decline in the forced expiratory volume in one second (FEV1) from the best (baseline) post-transplantation value, and is a major cause of mortality amongst lung and stem cell transplant patients. ${ }^{2}$ Severity of the disease is further characterized by successive stages based on the extent of lung function abnormality, where FEV1 measurements of FEV1 are 81-90\% (potential BOS), 66-80\% of baseline (Stage 1), $51-65 \%$ of baseline (Stage 2) or $\leq 50 \%$ of baseline (Stage 3). BOS affects $50 \%$ of all lung transplant patients within the first 5 years post-transplant and this rises to $80 \%$ within 10 years of transplant. ${ }^{3,4}$

These proportions illustrate the progressive nature of BOS but this condition also presents at least three challenges to elucidating its total costs and associated impact on the health care budget. Firstly, whereas rates of acute rejection have declined with the practice of immunosuppression interventions, the rates of chronic rejection leading to BOS have not similarly improved. ${ }^{5}$ Secondly, the lungs can develop BOS secondary to transplantation of other organ systems. As such, BOS becomes a major risk arising from chronic rejection of HSCT, where it is known to occur with a prevalence of 5.5\%., 3,6 Thirdly, while proportionally fewer HSCT patients will develop BOS as compared with lung transplant patients, the use of HSCT is increasing, as is the annual rate of lung transplantations being performed word-wide, with a concomitant increase in the absolute numbers of transplant-related BOS. Thus, estimating the cost of BOS requires a thorough look at multifactorial, time-delayed events in a heterogeneous population with overlapping clinical pathways. ${ }^{7,48}$

Given this complexity, it comes as little surprise that there have been few published studies focusing on the economic burden of BOS. Several studies have evaluated the cost-effectiveness of lung transplantation more broadly, with world-wide estimates ranging from $\$ 30000$ to $\$ 150000$ USD per quality-adjusted life year (QALY), ranges that vacillate between acceptable and unacceptable cost-effectiveness thresholds, depending on the setting. ${ }^{910,11,12,13}$ Most of these cost-effectiveness studies used healthcare costs as the numerator and QALYs as the denominator, yielding what is termed a cost-utility ratio. ${ }^{15,16}$ While this approach is good for planning allocation of scarce healthcare resources, it fails to capture the time burden that is required to care for transplant recipients and BOS patients, in particular, as well as lost work time or lost opportunities for paid employment. ${ }^{17}$ For example, a study comprising 53 lung transplant patients followed for 18 months in Holland reported that follow up healthcare was $\$ 600$ USD/week $(73 \%)$ higher in patients with BOS as compared to those without BOS. ${ }^{14}$ This elevated cost was predominantly associated with length of hospitalization and increased medication use. The development of BOS has also been reported to require approximately an additional 2-7 hospital days. ${ }^{14}$ From a health care services perspective, therefore, average BOS estimates can be multiplied by the average hospital and pharmaceutical costs that are incurred, using charge and billing records. However, BOS also affects social, labor, education, and other human capital values that benefit society. ${ }^{18,19,20,21}$ As we illustrate in this study, the majority of the BOS burden arises in the counterfactual, i.e. what would have been possible without the disease in terms of opportunities for paid employment over the remainder of a patient's disease-free life.

In the case of HSCT, a cost-benefit analysis of hematopoietic stem cell patients in the United Kingdom reported that hospital readmission costs in those with graft-versus-host-disease (GvHD), a risk factor for BOS, were double as compared to those without GvHD. ${ }^{21}$ Such equated to an additional $\$ 25000(£, 15000)$ in costs. While these studies have not defined the burden outright, they set an excellent groundwork for estimating 
the complex economic burden of BOS.

\section{METHODS}

\section{Data Sources}

Within a broad interpretation of the value of a statistical life, we estimated a BOS-specific societal burden of cost resulting from a conservative combination of lost human capital and added medical expenditures. ${ }^{23}$ From this wider societal perspective, total cost surrounding BOS over the next decade was evaluated based on the formula: Total Cost $(\mathrm{TC})=$ Prevalent Population $(\mathrm{PP}) *($ Medical Cost $(\mathrm{MC})+$ Lost Wages $(\mathrm{LWT})) *$ time $(\mathrm{t}$ in years).

The data populating this formula were derived from several population-based databases and secondary sources, as thusly described. Transplant statistics were gathered using data from both the United Network for Organ Sharing at the Health Resources and Services Administration (HRSA) and the Leukemia and Lymphoma Society (LLS). Prevalence of BOS, time delay to onset treatment costs, family and caregiver costs and average wage assumptions for the United States (SSA.gov) were summated and projected over a ten-year time horizon for the predicted BOS population in 2025.3,4,24,25,26,27 Inflationary adjustments were applied based on indices reported by the Bureau of Labor Statistics (BLS). ${ }^{28}$

In our estimate of the wider societal burden of the disease, BOS patients were conservatively (at the outer bound of the model) assumed to have received a diagnosis within 5 years post-transplant, with approximately $25-30 \%$ being employed prior to transplant. ${ }^{29,30}$ This is not to overlook the possibility that unemployment prior to BOS may have also been due to a loss of functional ability. We used the latter figure of $30 \%$ prior employment for our 10 -year prospective calculations, but incorporated a range down to $25 \%$ in our sensitivity analysis.

Whereas physical functioning may restore to normative ranges following successful transplant, few BOS patients ultimately are able to return to the work force. ${ }^{31}$ However, while the literature shows that BOS patients are unlikely to return to normative levels of physical and psychological functioning there is little to suggest that this is due to any increase in disability attributed to BOS. ${ }^{32,33}$ In fact, one study has shown that even psychological stress impacting employability is not significantly increased by BOS over initial lung transplantation. ${ }^{34}$ Instead, the impact of BOS on employment is caused by BOS representing a major cause of mortality amongst lung transplant recipients. Therefore, our sensitivity analysis included estimates of work years lost based on a range of employment outcomes, while our baseline calculation used the average for lung transplantation.

\section{Analysis}

The LLS report titled, "Blood Marrow and Stem Cell Transplantation" provides an incidence of 7000 HSCTs in North America during 2013. ${ }^{25}$ With a 5-year 5.5\% incidence rate of BOS amongst HSCTs, this creates 385 incident patients every year. ${ }^{26}$ The incidence of lung transplants was adapted from statistics reported by UNOS, and the International Society for Heart \& Lung Transplantation (ISHLT). A 5-year 50\% occurrence of BOS was applied to populations at risk for BOS, yielding an annual average of 904.4 diagnoses that are consequent to lung transplants. This figure is based on a total of 4522 cases of BOS observed over five-years, specifically from lung transplants. ${ }^{26}$ Added to this is the average of 385 incident cases of BOS resulting from HSCT. In both cases, HSCT and lung transplant, five years of incidence data were used to derive a 2015 combined prevalence that accounted for mortality. For the purposes of creating a ten year burden of cost, this 
prevalence was then added to 10 years of incidence statistics for both sources of BOS patients.

\section{Sensitivity Analysis}

A sensitivity analysis was performed to test the robustness of our assumptions. There is no clear consensus on how long a BOS survivor may take before returning to work, other than the average time to mortality (Dudek et al., 2003), nor is the average age of BOS patients clear (perhaps this is documented in ISHLT registry data slides/website, cf. my previous email), aside from using the average age of lung transplant recipients (HRSA). ${ }^{36,24}$ Therefore, we varied the average duration of sickness for survivors, the average years lost to mortality, the average employment rate prior to lung transplant and the percentage of survivors who are able to ultimately return to the work force. As table two shows, only the average number of years lost to mortalitywhich reflects the average age of patients-has a strong influence on the outcome. This is because the number of survivors is so low that their ability to return to the workforce has a negligible impact on the vast overall costs of BOS. A lesser but still influential relationship is show when using the low estimate in the literature for prior employment.

\section{RESULTS}

A total of $14771 \mathrm{BOS}$ patients were estimated from the last 5 years of trends reported in the registries to require treatment over the next decade (from 2015 to 2025). These patients will accrue a total of 82744 years of lost wages. This lost workforce will cost society $\$ 3714235976.76$ (\$3.7B) over the next decade, a figure that is more than 2.7X ( $\$ 3.7 \mathrm{~B}$ vs. $\$ 1.3 \mathrm{~B})$ the estimated ten-year cost of treating BOS (\$1353 120580$)$, including diagnostics, immunosuppressives, and additional complications. ${ }^{14}$ As such, BOS is estimated to present a conservative burden of cost that will exceed $\$ 5$ billion over the next decade in the United States alone (See Table 1). The sensitivity analysis shows that the average age of the patient, which is reflected in the number of work years lost to mortality, has the highest effect on outcomes. A 10 -year change in the average years lost results in a $40 \%$ change in total burden of cost-without changing the medical cost.

Table 1. Present and 10-year Burden of Cost for BOS

\begin{tabular}{lrrr}
\hline Calculation & & & \\
\hline \multicolumn{1}{c}{ HCT } & Lung & Total \\
\hline Estimated Prevalence & 608 & 1433 & 2041 \\
Estimated Incidence & 385 & 847 & 1232 \\
Ten Year Incidence & 3850 & 8880 & 12730 \\
Total & 4458 & 10313 & 14771 \\
Statistical Years of Lost Wages & 82744 & & \\
Ten Year Medical Cost & $\$ 1353120580.63$ & & \\
Lost Wages $_{\text {Total }}{ }^{1}$ & $\$ 3714235976$ & & \\
\hline
\end{tabular}

${ }^{1}$ Only $30 \%$ of total lung transplant patients are reported as being employed prior to lung transplant (Singer et al., 2014). 
Table 2. Sensitivity Analysis

\begin{tabular}{|c|c|c|c|c|c|}
\hline Analysis & & Years Lost & Wages Lost & $\begin{array}{c}\text { Total W/ } \\
\text { Medical Cost }\end{array}$ & $\begin{array}{l}\% \text { Total } \\
\text { Change }\end{array}$ \\
\hline \multicolumn{6}{|l|}{ Baseline } \\
\hline & & 82744 & $\$ 3714235976$ & $\$ 5067356557$ & $\mathrm{n} / \mathrm{a}$ \\
\hline \multicolumn{6}{|l|}{ Prior Employment } \\
\hline & 0.25 & 54859.30 & $\$ 2462533400.60$ & $\$ 3815653981.23$ & $24.701 \%$ \\
\hline \multicolumn{6}{|c|}{ Percent Disabled Survivors } \\
\hline & 0.75 & 81716.35 & $\$ 3668096999.65$ & $\$ 5021217580.28$ & $-0.911 \%$ \\
\hline & 0.50 & 76577.03 & $\$ 3437402114.12$ & $\$ 4790522694.75$ & $-5.463 \%$ \\
\hline & 0.25 & 71437.70 & $\$ 3206707228.58$ & $\$ 4559827809.21$ & $-10.016 \%$ \\
\hline \multicolumn{6}{|c|}{ Years Lost to Mortality } \\
\hline & 10 & 42445.27 & $\$ 1905290483.97$ & $\$ 3258411064.60$ & $-35.698 \%$ \\
\hline & 30 & 126401.41 & $\$ 2744180976.83$ & $\$ 4097301557.46$ & $38.637 \%$ \\
\hline & 50 & 172980.63 & $\$ 7764782384.87$ & $\$ 9117902965.50$ & $79.934 \%$ \\
\hline \multicolumn{6}{|c|}{ Survivors' Duration of Sickness } \\
\hline & 4 & 83211.44 & $\$ 3735208239.08$ & $\$ 5088328819.71$ & $0.414 \%$ \\
\hline & 5 & 83445.04 & $\$ 3745694370.24$ & $\$ 5098814950.87$ & $0.621 \%$ \\
\hline & 6 & 83678.65 & $\$ 3756180501.40$ & $\$ 5109301082.03$ & $0.828 \%$ \\
\hline
\end{tabular}

\section{DISCUSSION}

Lung transplantation has become a viable treatment option for many end-stage lung diseases such as cystic fibrosis, chronic obstructive pulmonary disease (COPD), idiopathic pulmonary fibrosis and alpha-1 antitrypsin deficiency. While solid organ transplants have generally evolved in terms of donor-match efficiency and infection prevention, donor lungs still presents much higher rates of complication and rejection than other solid organ transplants, both immediately following surgery and throughout the patient's life. Moreover, the delayed-onset nature of BOS means that its prevalence overshadows its incidence, which leads to a surprising number of cases that exceed what would otherwise be expected from HSCT and lung transplant statistics in a mere one-year snapshot.

We compared contributors to the total cost of BOS as well as the sensitivity surrounding our assumptions. We counted lung transplants as having a uniform cost for a single lung; inclusion of double lung transplants would intensify our conclusions. As expected, the average age of patients had a strong impact on our results. Even extreme variation in patient recovery time and ability to return to work has little impact on the overall cost of BOS, because of the severe mortality associated. We found that even conservative estimates of collective lost work time can trump the medical cost of treating BOS in the decade ahead. Stated another way, the consequence is lost work time that amounts to a societal deficit that can be measured in billions of dollars and compared against the marginal cost of treatment. Improving measures of donor compatibility, shortening the time end-stage lung failure patients wait for a transplant and streamlining the donor referral process will only go so far towards reducing the risk of lung rejection; they will not eliminate it.

The impact of BOS is very different from other end-of-life diseases. The trends towards increasing numbers of transplants among a relatively young population suggest that burden of BOS will only continue to rise in the years ahead. According to the US Organ Procurement and Transplantation Network at HRSA there have been 
604,434 lung transplants performed in the United States, with 68 active lung transplant programs currently underway (as of 25 July 2014). The 1653 patients who are actively awaiting lungs as of 1st August are in addition to the more than 10000 people living with a transplanted lung (HRSA). According to the same registry, there were double the number of lung transplants performed in 2013 as compared with just over a decade earlier (1923 vs. 959 in 2000; adjusted mean age 45.4 years). ${ }^{35}$

\section{CONCLUSIONS}

BOS will continue to present a substantial economic burden to society that extends far beyond its direct healthcare cost, due in large part to the foreshortened departure of thousands from the paid workforce. This rising burden of illness surrounding BOS is likely to receive greater attention given the movement towards precision medicine and wider societal pressure to contain costs. As with any other disease that threatens the lives and livelihoods of hitherto active members of society and their families, BOS should be viewed in its totality to include both the wider human capital perspective and a multi-year time horizon.

\section{ACKNOWLEDGMENTS}

DGC is a recipient of a CJ Martin Fellowship from the National Health and Medical Research Council of Australia (\# 1053790). CAJ is principal of ForMyOdds LLC a corporation that received sponsorship from Therakos Inc to perform inter alia this analysis. RV is supported by the Research Foundation Flanders (FWO) (KAN2014 1.5.139.14) and Klinisch Onderzoeksfonds (KOF) KU Leuven.

\section{REFERENCES}

${ }^{1}$ Barker AF, Bergeron A, Rom WN, Hertz MI: Obliterative bronchiolitis. N Engl J Med 2009;370(19).

${ }^{2}$ Meyer KC, Raghu G, Verleden GM, et al: An international ISHLT/ATS/ERS clinical practice guideline: diagnosis and management of bronchiolitis obliterans syndrome. Eur Respir J 2014;44(6).

${ }^{3}$ Christie JD, Edwards LB, Kucheryavaya AY, et al: The Registry of the International Society for Heart and Lung Transplantation: 29th adult lung and heart-lung transplant report. J Heart Lung Transplant 2012;31(10):107386.

${ }^{4}$ Yusen RD, Christie JD, Edwards LB, et al: The Registry of the International Society for Heart and Lung Transplantation: Thirtieth adult lung and heart-lung transplant report--2013; focus theme: Age. J Heart Lung Transplant 2013;32(10):965-78.

${ }^{5}$ Scheffert JL, Raza K: Immunosuppression in lung transplantation. J Thoracic Dis 2014;6(8):1039-53.

${ }^{6} \mathrm{Au} \mathrm{BK}$, Au MA, Chien JW: Bronchiolitis obliterans syndrome epidemiology after allogeneic hematopoietic cell transplantation. Biol Blood Marrow Transplant 2011;17(7):1072-8.

${ }^{7}$ Gratwohl A, Baldomero H, Schwendener A, et al: Predictability of hematopoietic stem cell transplantation rates. Haematologica 2009;92(12):1679-86.

${ }^{8}$ Jones CA, Callas PW, Everett RW, et al: An algorithm to analyze cost heterogeneity using counterfactual scenarios in endovascular versus open repair of abdominal aortic aneurysm: Predicting costs for subsequent patients JHEOR 2014;1(3):308-21.

${ }^{9}$ Verleden SE, Vasilescu DM, Willems S, et al: The site and nature of airway obstruction after lung transplantation. Am J Respir Crit Care Med 2014;189(3):292-300. 
${ }^{10}$ Anyanwu AC, McGuire A, Rogers CA, Murday AJ: An economic evaluation of lung transplantation. J Thorac Cardiovasc Surg 2002;123(3):411-8; discussion 8-20.

${ }^{11}$ Groen H, Van Der Bij W, Koëter GH, TenVergert EM: Cost-effectiveness of lung transplantation in relation to type of end-stage pulmonary disease. Am J Transplant 2004;4(7):1155-62.

${ }^{12}$ Ouwens JP, van Enckevort PJ, TenVergert EM, et al: The cost effectiveness of lung transplantation compared with that of heart and liver transplantation in the Netherlands. Transplant Int 2003;16(2):123-7.

${ }^{13}$ Vasiliadis HM, Collet JP, Penrod JR, Ferraro P, Poirier C: A cost-effectiveness and cost-utility study of lung transplantation. J Heart Lung Transplant 2005;24(9):1275-83.

${ }^{14}$ van den Berg JW, van Enckevort PJ, TenVergert EM, Postma DS, van der Bij W, Koeter GH: Bronchiolitis obliterans syndrome and additional costs of lung transplantation. Chest 2000;118(6):1648.

15 Zeckhauser R, Shepard D: Where Now for Saving Lives? Law Contemp Problems 1976;40(4):45.

${ }^{16}$ Russell LB, Gold MR, Siegel JE, Daniels N, Weinstein MC: The role of cost-effectiveness analysis in health and medicine. Panel on cost-effectiveness in health and medicine. JAMA 1996; 276(14):1172-7.

${ }^{17} \mathrm{Xu}$ J, Adeboyejo O, Wagley E, et al: Daily burdens of recipients and family caregivers after lung transplant. Progress Transplantation 2012;22(1):41-8.

${ }^{18}$ Becker G, Murphy K, Philipson T: The value of life near its end and terminal care. NBER working paper series. Working paper 13333. http://www.nber.org/papers/w13333. 2007. Accessed February 10, 2015.

${ }^{19}$ Boldizzoni: Means and ends: the idea of capital in the West; 1500-1970. New York: Palgrave Macmillan. 2008.

${ }^{20}$ Little WA: Motivating learning and the development of human capital. Compare 2003;33(4):437-52.

${ }^{21}$ Kwon DB: Human Capital and its Measurement. 3rd OECD World Forum on "Statistics, Knowledge and Policy". Busan, Korea 27-30 October 2009. http://www.oecdworldforum2009.org. Accessed February 10, 2015.

${ }^{22}$ Dignan FL, Potter MN, Ethell ME, et al: High readmission rates are associated with a significant economic burden and poor outcome in patients with grade III/IV acute GvHD. Clin Transplant 2013;27(1):E56-63.

${ }^{23}$ Viscusi W, Aldy JE: The value of a statistical life: Acritical review of market estimates throughout the world (February 2003). NBER Working Paper No. w9487.

${ }^{24}$ HRSA.gov: Lung transplants in the US by recipient age. http://optn.transplant.hrsa.gov/converge/ latestData/rptData.asp. Accessed February 10, 2015.

25 LLS.org: Blood and Marrow Stem Cell Transplantation. https://www.lls.org/content/nationalcontent/ resourcecenter/freeducationmaterials/treatments/pdf/bloodmarrowstemcelltransplantation.pdf. Accessed February 10, 2015.

${ }^{26}$ Chien JW, Duncan S, Williams KM, Pavletic SZ: Bronchiolitis obliterans syndrome after allogeneic hematopoietic stem cell transplantation - An increasingly recognized manifestation of chronic graft-versushost disease. Biology of blood and marrow transplantation. J Am Soc Blood Marrow Transplant 2010;16(1 Suppl):S106-14.

${ }^{27}$ SSA.gov: National Average Wage Index. http://www.ssa.gov/oact/cola/AWI.html. Accessed February 10, 2015.

${ }^{28}$ BLS.gov: CPI Inflation Calculator. http://data.bls.gov/cgi-bin/cpicalc.pl. Accessed February 10, 2015.

${ }^{29}$ Littlefield C, Abbey S, Fiducia D, et al: Quality of life following transplantation of the heart, liver, and lungs. Gen Hosp Psychiatry 1996;18:36S-47S. 
${ }^{30}$ Singer JP, Blanc PD, Dean YM, et al: Development and validation of a lung transplant-specific disability questionnaire. Thorax 2014;69(5):437-42.

${ }^{31}$ Finlen Copeland CA, Vock DM, Pieper K, Mark DB, Palmer SM: Impact of lung transplantation on recipient quality of life: a serial, prospective, multicenter analysis through the first posttransplant year. Chest 2013;143(3):744-50.

32 Vermeulen KM, Groen H, van der Bij W, Erasmus ME, Koeter GH, TenVergert EM: The effect of bronchiolitis obliterans syndrome on health related quality of life. Clin Transplant 2004;18(4):377-83.

${ }^{33}$ Kunsebeck HW, Kugler C, Fischer S, et al: Quality of life and bronchiolitis obliterans syndrome in patients after lung transplantation. Prog Transplant 2007;17(2):136-41.

${ }^{34}$ Goetzmann, L, Irani S, Schwegler K, et al: Lung function, sociodemographic characteristics, and psychological reaction to transplant associated with chronic stress among lung recipients. Anxiety Stress Coping 2010;23(2):21323.

${ }^{35}$ Ishlt.org: International Society for Heart \& Lung Transplantation 2014 Transplant Registry. http:/ /www.ishlt. org/registries/slides.asp?slides=heartLungRegistry. Accessed March 30, 2015.

${ }^{36}$ Dudek AZ, Mahaseth H, DeFor TE, Weisdorf DJ: Bronchiolitis obliterans in chronic graft-versus-host disease: analysis of risk factors and treatment outcomes. Biol Blood Marrow Transplant 2003;9(10):657-66. 